\title{
Helen Bynum. Spitting Blood. History of Tuberculosis. United Kingdom: Oxford University Press, 2012
}

DOI: http://dx.doi.org/10.15648/hc.27.2015.9

Dentro de la historiografía sobre salud pública tenemos el texto de Helen Bynum, historiadora inglesa. Ella aborda una enfermedad bastante conocida por nosotros. Es más muy pocos padecimientos se pueden relacionar tanto con nuestro pasado como la tuberculosis. Desde la antigüedad hasta ahora, Helen Bynum trata de estudiarlo abordándolo desde su impacto social y no solo sanitario. Aunque la autora busca mirar su problema de estudio desde una perspectiva global se concentra principalmente en el Reino Unido y Estados Unidos.

El libro comienza con un prólogo que relata la vida de George Orwel (1903-1950). Tomando como excusa la vida del escritor inglés, la autora nos muestra el proceso de transmisión y desarrollo de la enfermedad. Orwel escribió su más famoso libro titulado 1984, cuando se encontraba muy enfermo; luego de su publicación fallecería asfixiado en su propia sangre luego de sufrir una hemorragia en una nueva etapa en la lucha contra este mal. Para esta época se desarrollaron los antibióticos que la combatían y paradójicamente, Orwel murió debido a que no fue posible iniciarle el tratamiento de estreptomicina porque tuvo fuertes reacciones alérgicas.

La tuberculosis es una enfermedad social. Existen pruebas de registro arqueológico de la Mycobacterium tuberculosis en los huesos humanos alrededor del 5.800 a.C., es decir que la bacteria y sus huéspedes humanos han estado juntos por un largo tiempo. Los griegos ya la conocían; fue llamada tisis, 
nombre con que la conocemos aún en la actualidad. Hipócrates describía la tos y los escupitajos de sangre como señales de muerte.

Desde la época medieval hasta la actualidad, Helen Bynum explora la historia y el desarrollo de la tuberculosis, tocando los diversos descubrimientos que han surgido alrededor de la enfermedad a través del tiempo y se centra en los enfoques experimentales de René Laennec (1781-1826) y Robert Koch (1842-1910). La autora muestra cómo, a pesar de ser una enfermedad de predominio mundial, los avances científicos, que lograron develar lo que era una misteriosa infección a una patología bacteriana curable, fueron producto de una medicina europea continental que se encontraba en su máximo esplendor. Sin embargo, este predominio fue superado por los Estados Unidos, que alcanzaron el máximo logro en la historia de la tuberculosis, cuando Selma Abraham Waksman (1888-1973) forjó una alianza entre la investigación universitaria estadounidense y la industria farmacéutica para crear la colaboración que produjo la estreptomicina, poderoso antibiótico que la volvió menos mortal.

A partir de 1950, el devenir histórico de esta enfermedad se vuelve cada vez más complejo, debido al surgimiento de la Organización Mundial de la Salud (OMS) y las inmensas dificultades que tuvo en implementar las medidas sanitarias para tratar y prevenir esta enfermedad en el mundo.

Bynum también examina el lugar de la tuberculosis en el imaginario popular y su papel en las diversas formas de arte. Estudiando cómo esta ha estado ligada a grandes literatos como Lord Byron (1788-1824), John Keats (1795-1821) y Robert Louis Stevenson (1850-1894), ha llevado a relacionarla con imágenes románticas de estas grandes figuras consumidas por la enfermedad derramando su ingenio en las obras creativas.

Pero más allá de los nombres famosos, Spitting Blood nos muestra un argumento convincentemente grave, que a pesar de siglos de esfuerzo científico esta enfermedad sigue cobrando la vida de miles de seres humanos. Cada año, se contagian alrededor de 9 millones de personas y causa la muerte de 1,4 millones. La autora muestra cómo estos contagios se encuentran en los países en desarrollo, llevando a que muchos paralicen su 
economía debido a la muerte de una parte de la fuerza de trabajo, ya que sus consecuencias son más nefastas entre más joven sea el paciente. La tuberculosis ha regresado con virulencia a Occidente ligada a una nueva infección -VIH- conjugada con la resistencia a los medicamentos; todo esto demuestra que su historia está lejos de terminar y aún existe mucho por estudiar.

\section{Ángela Lucía Agudelo González Profesora Tiempo Completo Universidad del Tolima alago22@gmail.com}

